\title{
PERFIL DOS PACIENTES ATENDIDOS EM AMBULATÓRIO DE GENÉTICA MÉDICA EM UM CENTRO UNIVERSITÁRIO DE BELÉM, PARÁ, AMAZÔNIA
}

\section{ARTIGO ORIGINAL}

LIMA, Gabriela Elenor dos Santos ${ }^{1}$, MARTINS, Carlos Henrique Lopes$^{2}$, DENDASCK, Carla Viana ${ }^{3}$, OLIVEIRA, Ciane Martins de ${ }^{4}$, OLIVEIRA, Euzébio de ${ }^{5}$

LIMA, Gabriela Elenor dos Santos. Et al. Perfil dos pacientes atendidos em ambulatório de genética médica em um Centro Universitário De Belém, Pará, Amazônia. Revista Científica Multidisciplinar Núcleo do Conhecimento. Ano 06, Ed. 03, Vol. 11, pp. 48-62. Março de 2021. ISSN: 2448-0959, Link de acesso: https://www.nucleodoconhecimento.com.br/saude/ambulatorio-de-genetica, DOI: 10.32749/nucleodoconhecimento.com.br/saude/ambulatorio-de-genetica

\section{RESUMO}

A Genética Médica (GM) tornou-se uma especialidade médica reconhecida, com conceitos e abordagens importantes no diagnóstico e tratamento de muitas doenças, comuns e raras. As doenças genéticas seguem padrões de herança, podendo ser autossômicas recessivas, autossômicas dominantes, ligadas ao cromossomo X ou ao cromossomo $\mathrm{Y}$, ou multifatoriais. O objetivo do estudo foi determinar o perfil dos pacientes atendidos em um ambulatório de GM, em um Centro Universitário de Belém, no Estado do Pará. Os dados foram coletados a partir de prontuários de pacientes, atendidos entre 2014 e 2019, com o uso de questionário próprio dos

\footnotetext{
${ }^{1}$ Acadêmica de Medicina do Centro Universitário do Estado do Pará - CESUPA.

${ }^{2}$ Acadêmico de Medicina do Centro Universitário do Estado do Pará - CESUPA.

${ }^{3}$ Teóloga, Doutora em Psicanálise Clínica. Atua há 15 anos com Metodologia Científica ( Método de Pesquisa) na Orientação de Produção Científica de Mestrandos e Doutorandos. Especialista em Pesquisas de Mercado e Pesquisas voltadas a área da Saúde.

${ }^{4}$ Doutora em Genética Médica. Docente e Pesquisadora do Centro Universitário do Estado do Pará (CESUPA).

${ }^{5}$ Doutor em Medicina/Doenças Tropicais. Docente e Pesquisador na Universidade Federal do Pará - UFPA.
}

RC: 79751

Disponível em: https://www.nucleodoconhecimento.com.br/saude/ambulatorio-de- 
pesquisadores, com dados analisados e tabulados através do programa Microsoft Excel. Foram analisados 101 prontuários, com predominância do sexo feminino (51 pacientes). Além disso, a maior parte dos atendimentos foi destinado às crianças $(41,5 \%)$. No tocante à etnia, foram observadas apenas as variáveis "branco" e "pardo", com prevalência maior de pacientes pardos (78 do total). Também, Belém foi a cidade mais prevalente na naturalidade dos pacientes (61 registros). As especialidades com maior número de encaminhamentos para o ambulatório de GM foram a Endocrinologia e a Neurologia, sendo o Atraso do Desenvolvimento Neuropsicomotor, o diagnóstico mais frequente. Em 42 prontuários, a idade ao diagnóstico não estava presente. Dos 101 pacientes, somente 16 tiveram aconselhamento genético e nos 85 restantes não havia registro sobre esta informação. Por fim, a idade materna ao nascimento não foi encontrada na maioria dos prontuários (ausente em 61,38\%). Assim, elaborar um perfil do paciente atendido em um ambulatório de GM é importante, uma vez que se torna possível identificar eventuais falhas no serviço prestado, além de adequar a relação médicopaciente.

Palavras-Chave: Genética Médica, ambulatório, doenças genéticas.

\section{INTRODUÇÃO}

A Genética surgiu na Medicina no início do século XX, quando foi percebido que as leis mendelianas da hereditariedade podiam explicar a recorrência de alguns transtornos familiares. Nos 100 anos seguintes, a Genética Médica (GM) deixou de ser uma pequena subespecialidade voltada para apenas poucos transtornos hereditários raros, para se tornar uma especialidade médica reconhecida, com conceitos e abordagens importantes no diagnóstico e tratamento de muitas doenças, tanto comuns quanto raras (NUSSBAUM et al., 2016).

A GM foi reconhecida como especialidade médica pelo Conselho Federal de Medicina no ano de 1983 e em 1986, para ampliar o conhecimento da especialidade,

RC: 79751

Disponível em: https://www.nucleodoconhecimento.com.br/saude/ambulatorio-de- 
foi criada a Sociedade Brasileira de Genética Médica. Mais recentemente, a GM tem atuado de forma relevante no aconselhamento genético (SOCIEDADE BRASILEIRA DE GENÉTICA MÉDICA, 2020).

Segundo a Organização Mundial da Saúde (OMS), o aconselhamento genético diz respeito a um esclarecimento de ordem genética, que tem por finalidade a prevenção de genótipos responsáveis por enfermidades ou defeitos congênitos, por meio de identificação prospectiva ou retrospectiva de uniões que podem produzir essas alterações. Além disso, o aconselhamento também abrange a comunicação dos problemas relacionados à ocorrência ou ao risco de ocorrência de uma doença genética na família. Por isso, é necessária a participação de uma equipe multidisciplinar de profissionais capazes de aconselhar o paciente e sua família quanto ao diagnóstico, ao curso da doença, às condutas disponíveis, ao risco de recorrência e alternativas para tal risco. Nesse contexto, destaca-se que o profissional que oferece $\mathrm{o}$ aconselhamento não pode sugerir, indicar ou exigir condutas aos pacientes atendidos por ele (BERTOLLO et al., 2013).

Uma doença de origem genética se origina de modificações nas sequências de Ácido Desoxirribonucleico (DNA), o material genético, de cada indivíduo ou de mutações à nível dos cromossomos sexuais ou autossômicos (GRIFFITHS; WESSLER; DOEBLEY, 2016).

As doenças genéticas seguem padrões de herança, podendo ser: (1) autossômicas recessivas, que se manifestam somente em indivíduos homozigotos para um gene autossômico, ou seja, os indivíduos afetados têm duas cópias do gene mutante, como exemplo, a fibrose cística, que resulta de uma mutação no gene CFTR no cromossomo 7, e a fenilcetonúria clássica, relacionada à mutações no gene localizado no cromossomo 12; (2) autossômicas dominantes, em que os genes mutantes também estão nos cromossomos autossomos, contudo, uma única cópia gênica é capaz de causar a doença, como o caso da Doença de Huntington; (3) ligadas ao cromossomo $\mathrm{X}$, também conhecidas como heranças ligadas ao sexo,

RC: 79751

Disponível em: https://www.nucleodoconhecimento.com.br/saude/ambulatorio-de- 
nesse caso, os cromossomos estão localizados em uma região não homóloga do cromossomo $\mathrm{X}$ e as mutações são dominantes no sexo masculino, os principais exemplos são daltonismo, hemofilia e distrofia muscular de Duchenne; (4) ligadas ao $\mathrm{Y}$, ou herança holândrica ou herança restrita ao sexo, em que a ocorrência da doença está relacionada ao cromossomo $Y$ na sua porção não homóloga ao cromossomo X; e (5) poligênicas ou multifatoriais, que resultam de mutações em genes diferentes ou surgem de interação de diversos fatores ambientais, daí o destaque para a região Amazônica do Brasil, devido a sua grande peculiaridade e diversidade de ambientes ecológicos e não ecológicos que que estão diretamente ligados a vida das pessoas e podem contribuir significativamente com alterações fenotípicas em múltiplos genes, por exemplo, doenças cardíacas coronárias, câncer e esquizofrenia (LOBO, 2008; BERTOLLO et al., 2013; NUSSBAUM et al., 2016).

As doenças genéticas também podem ser originadas de alterações cromossômicas, que são classificadas em: (1) mutações numéricas, em que há alteração no número de cromossomos da célula; e (2) mutações estruturais, em que há alteração na forma ou no tamanho dos cromossomos. Existem ainda casos em que pode ocorrer uma mistura de linhagens celulares, com presença de uma linhagem normal e uma outra alterada, evento chamado de mosaicismo (BORGES-OSÓRIO; ROBINSON, 2013).

As variações cromossômicas de caráter numérico classificam-se em duas grandes categorias principais: as euploidias e as aneuploidias. As euploidias envolvem genomas inteiros, afetando todos os cromossomos de um indivíduo, sendo uma condição incompatível com a vida. As aneuploidias envolvem alterações no número cromossômico, com aumento ou perda de um ou mais cromossomos, sem envolver o conjunto haploide (JORDE; CAREY; BAMSHAD, 2016).

No homem, essas alterações cromossômicas, em especial nos cromossomos maiores, são quase sempre letais, diferentemente do que ocorre em cromossomos menores, como é o caso do cromossomo 21 , que consegue se manter na linhagem

RC: 79751

Disponível em: https://www.nucleodoconhecimento.com.br/saude/ambulatorio-de- 
celular, embora acarrete em nascimentos com malformações físicas e mentais. Dentre as consequências geradas a partir de alterações cromossômicas, tem-se as síndromes de Down, de Edwards, de Patau e Klinefelter (ZANELLA; TERENCIO, 2016).

A partir do exposto, é válido ressaltar que, pelo fato das doenças genéticas serem uma condição sem cura, o acompanhamento é parte essencial do tratamento e perdura por toda a vida do paciente. Diante disso, o presente estudo tem por objetivo determinar o perfil dos pacientes atendidos em um ambulatório de GM, em um Centro Universitário de Belém, Pará, Amazônia.

\section{MATERIAL E MÉTODO}

Trata-se de um estudo descritivo e retrospectivo, em que foram analisados prontuários de pacientes atendidos no período de janeiro de 2014 a março de 2020, no ambulatório de GM do Centro de Especialidades Médicas de um Centro Universitário localizado na cidade de Belém, Pará. Todos os pacientes (mantido seu anonimato) assinaram Termo de Autorização para que os seus respectivos prontuários médicos pudessem ser analisados, para a coleta de dados, para o desenvolvimento da presente pesquisa. Este projeto foi submetido e aprovado pelo Comitê de Ética em Pesquisa com Seres Humanos, conforme o parecer de aprovação de número 2.917.287. Bem como o protocolo deste estudo seguiu rigorosamente as normas da Resolução nำ66/12 do Conselho Nacional de Saúde do Brasil (BRASIL, 2012), que estabelece normas para pesquisas envolvendo seres humanos.

Foram incluídos os prontuários dos pacientes atendidos somente no período referido para a realização desta pesquisa e excluídos os prontuários de pacientes atendidos nos ambulatórios de outras especialidades médicas. Foi analisado o perfil de cada paciente quanto às seguintes variáveis: sexo, idade, etnia, procedência, origem de encaminhamento médico, diagnóstico, idade quando do diagnóstico, idade da mãe

RC: 79751

Disponível em: https://www.nucleodoconhecimento.com.br/saude/ambulatorio-de- 
ao nascimento, intercorrências na gravidez, aconselhamento genético e acompanhamento destes pela equipe multiprofissional.

Os pacientes foram classificados, de acordo com a idade, seguindo os critérios da OMS, em crianças (até 9 anos), adolescentes (de 10 a 19 anos), adultos (de 20 a 59 anos) e idosos (a partir de 60 anos completos).

A coleta de dados, a partir da análise dos prontuários, foi feita utilizando questionário próprio dos pesquisadores, contendo questões objetivas e subjetivas. Os dados, então, foram tabulados e analisados com o auxílio do programa Microsoft Excel 2016.

\section{RESULTADOS}

Ao longo do período, foram analisados 101 prontuários. Destes, 49 eram de pacientes do sexo masculino e 51, do feminino (Figura 1). Além disso, constatou-se que a maior parte dos atendimentos foi destinada às crianças, com $41,5 \%$ do total, seguido de 31,68\% para os adolescentes e 20,79\% para os adultos. Os idosos representaram o menor percentual, com 5, 94\% dos atendimentos (Figura 2). É válido ressaltar que, do total de crianças, a maior frequência de registros foi de pacientes com 4 anos, encontrados na análise de 10 prontuários. Nas demais faixas etárias, a distribuição entre idades se mostrou semelhante.

RC: 79751

Disponível em: https://www.nucleodoconhecimento.com.br/saude/ambulatorio-de- 
Figura 1: Distribuição dos pacientes atendidos no ambulatório de Genética Médica, por sexo.

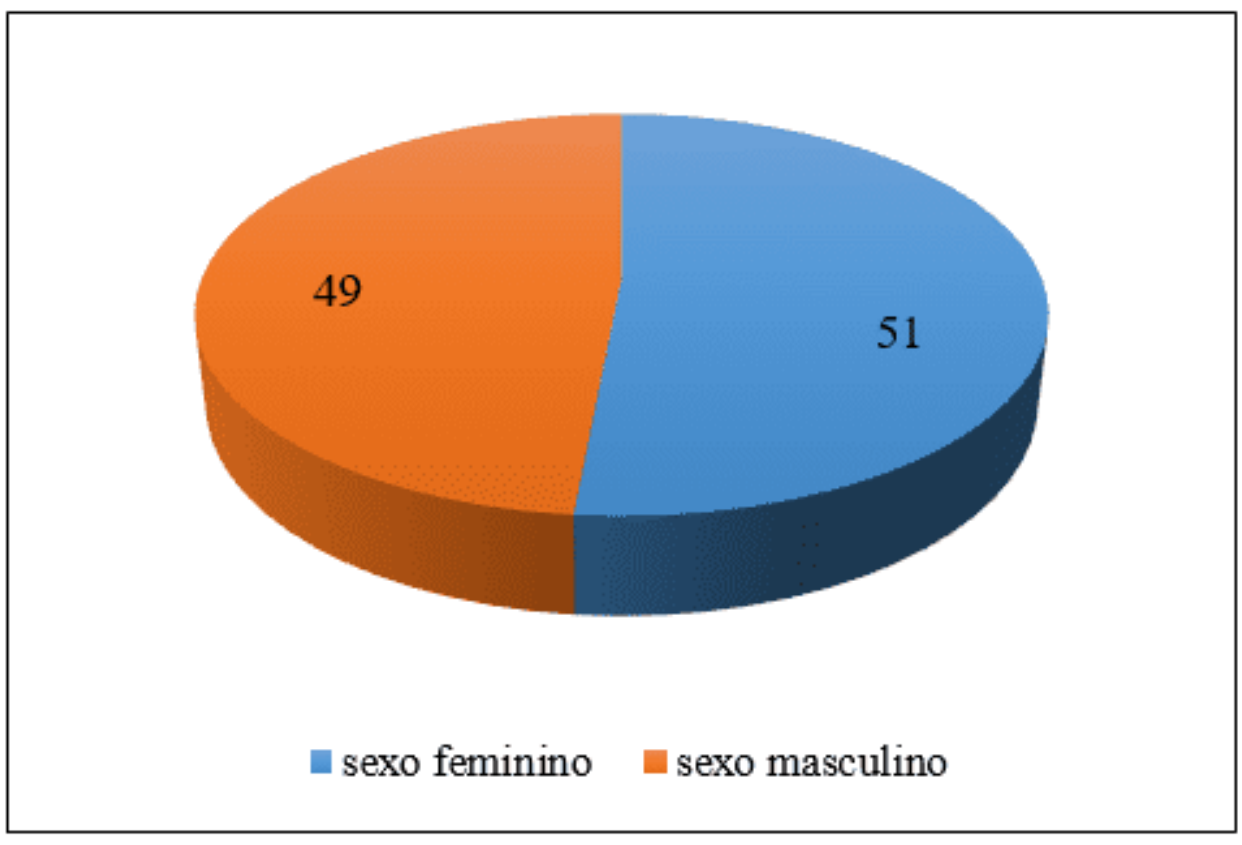

Fonte: Dados da pesquisa.

RC: 79751

Disponível em: https://www.nucleodoconhecimento.com.br/saude/ambulatorio-degenetica 
Figura 2: Distribuição dos pacientes atendidos no ambulatório de Genética Médica, por faixa etária.

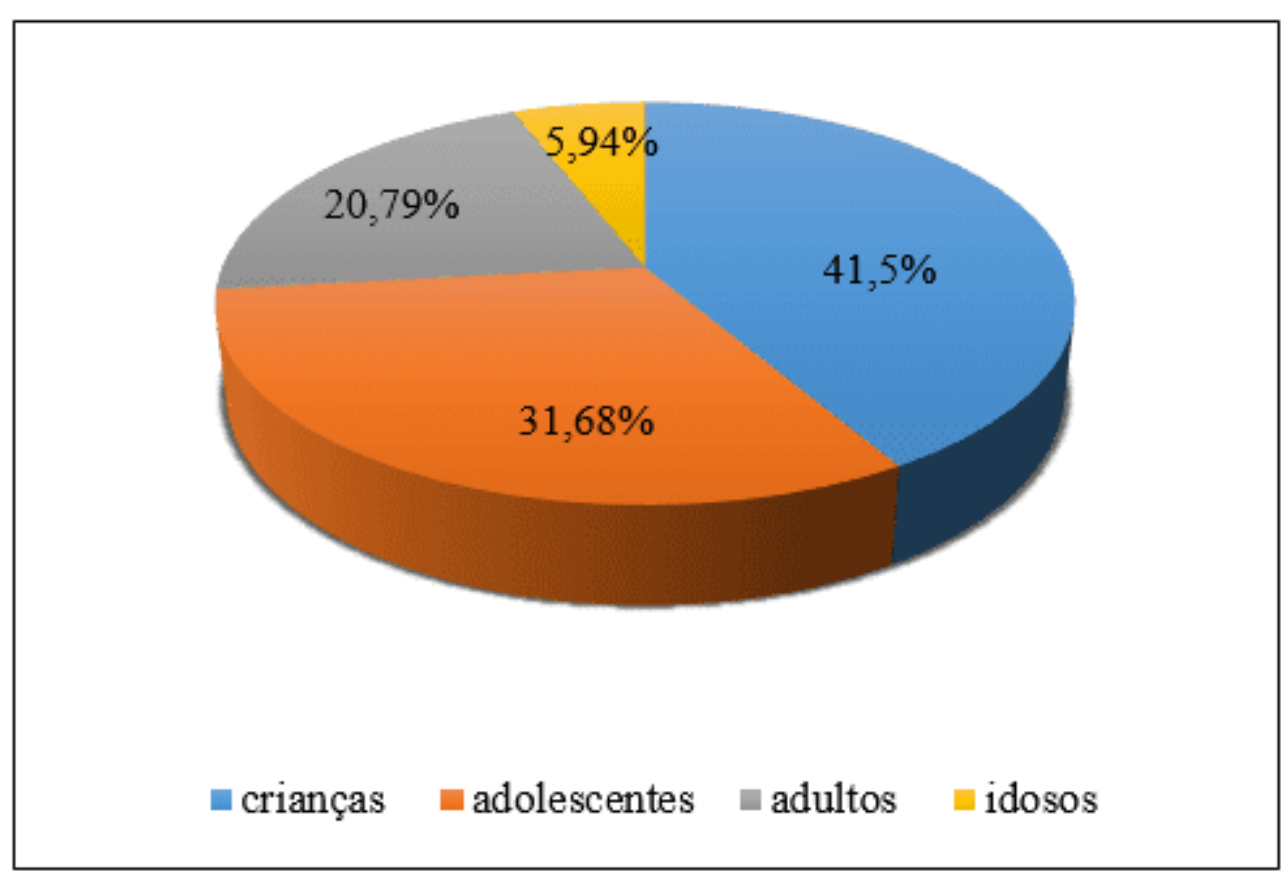

Fonte: Dados da pesquisa.

Em relação à etnia, durante a análise dos prontuários, foram encontradas as variáveis "branco" e "pardo", não tendo nenhum registro de paciente negro, além de haverem prontuários sem o preenchimento da questão. Dessa forma, houveram 10 pacientes brancos, 78 pardos e 13 em que não constava a informação.

Belém foi a cidade mais prevalente na naturalidade dos pacientes. A capital paraense concentrou 61 registros, seguida de Abaetetuba com 7 pacientes. Ressalta-se que, o ambulatório atendeu no período analisado, majoritariamente cidades que compõem a região metropolitana de Belém. Apenas 1 caso foi exceção: o de um paciente encaminhado do serviço de Genética de uma universidade de Campinas, no estado de São Paulo. Outras cidades encontradas no estudo foram Altamira (1), Ananindeua (4), Barcarena (3), Benevides (1), Bragança (3), Cametá

RC: 79751

Disponível em: https://www.nucleodoconhecimento.com.br/saude/ambulatorio-de- 
(4), Capanema (1), Castanhal (2), Cotijuba (1), Marabá (1), Marituba (1), Mosqueiro (2), Ourém (1), Paragominas (3), Portel (1), Santo Antônio do Tauá (1), Tucuruí (1) e Vigia (1) (Figura 3).

Figura 3: Distribuição dos pacientes atendidos no ambulatório de Genética Médica, por procedência.

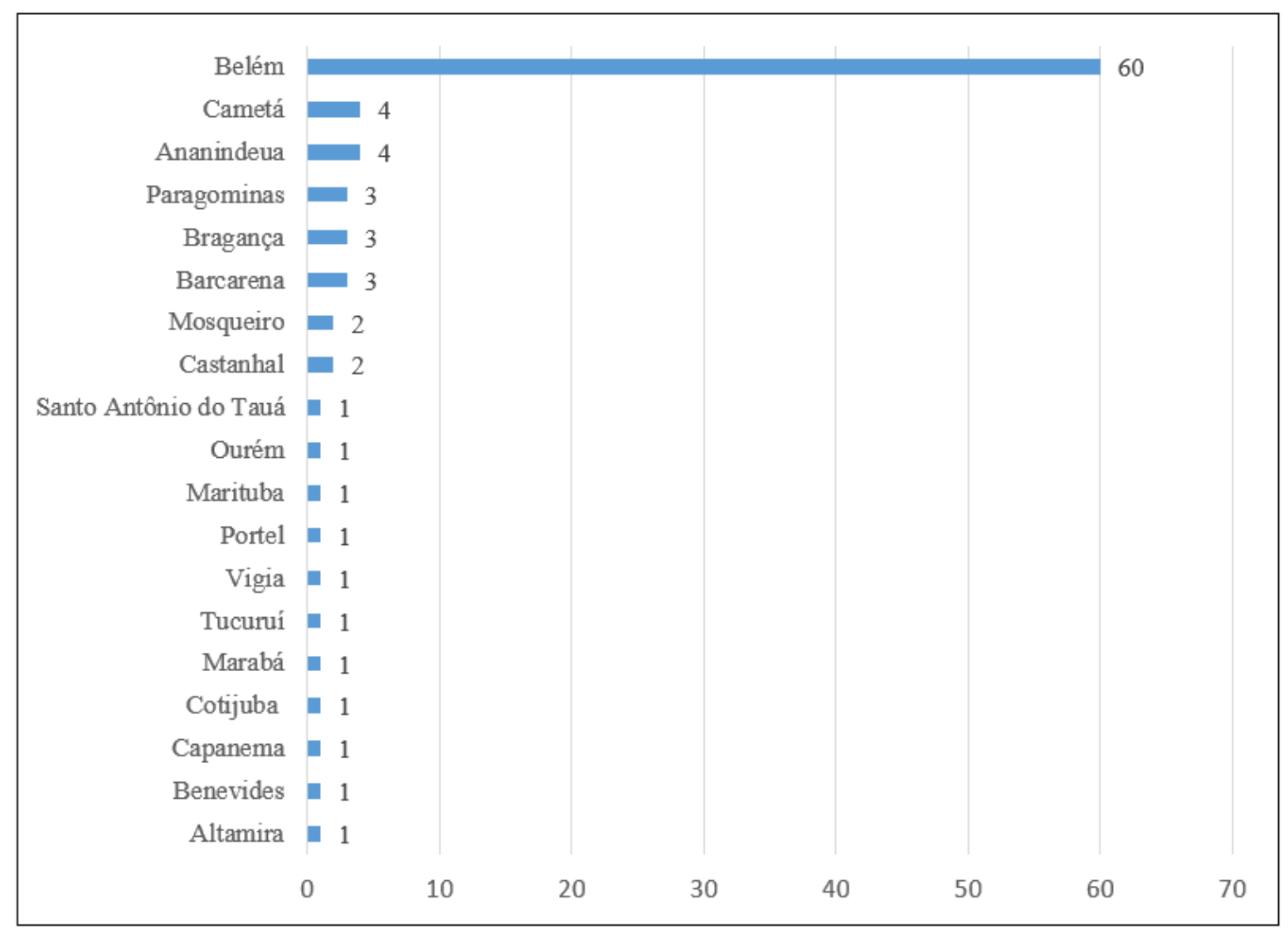

Fonte: Dados da pesquisa.

Constatou-se também que a Endocrinologia e a Neurologia são as especialidades com maior número de encaminhamentos médico para o ambulatório de GM. A Neurologia encaminhou 26 pacientes, com predomínio de crianças, sendo 25 pacientes pediátricos $(10,89 \%)$ e apenas 1 adulto. A Endocrinologia enviou 22 pacientes. Contudo, é grande também o número de prontuários em que não foi

RC: 79751

Disponível em: https://www.nucleodoconhecimento.com.br/saude/ambulatorio-degenetica 
encontrada essa informação, totalizando 26,73\%. Além dessas, outras especialidades médicas que encaminharam para a GM foram a Ginecologia (2), Mastologia (2), Neonatologia (2), Clínica Médica (1), Dermatologia (1), Gastropediatria (1), Genética da cidade de Campinas (1), Ortopedia (1), Pneumologia (1), Reumatologia (1), Saúde do Idoso (1) e Unidade Básica de Saúde (1) (Figura 4).

RC: 79751

Disponível em: https://www.nucleodoconhecimento.com.br/saude/ambulatorio-degenetica 
Figura 4: Distribuição dos pacientes atendidos no ambulatório de Genética Médica, por encaminhamento.

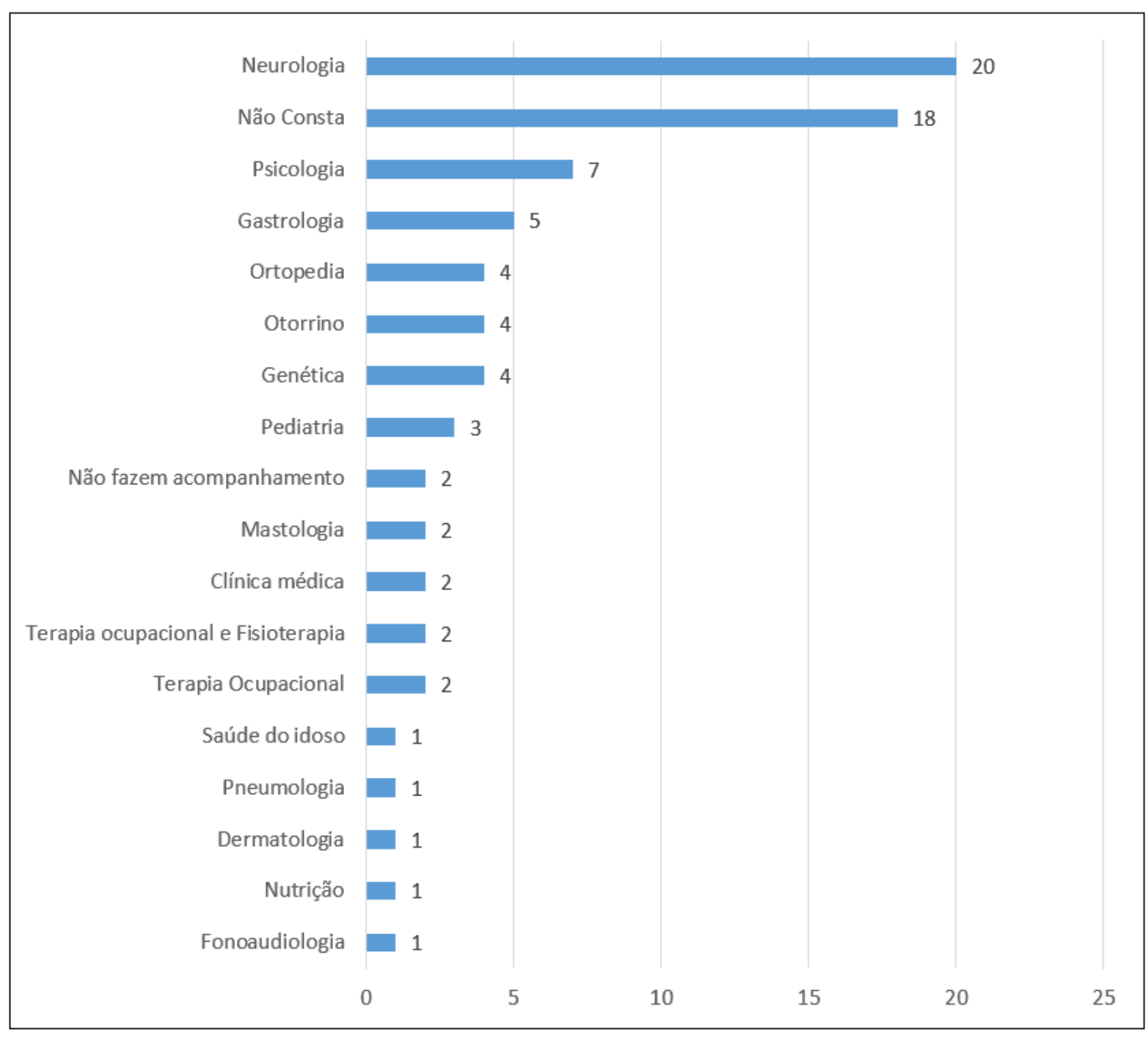

Fonte: Dados da pesquisa.

Os diagnósticos verificados foram diversificados. Raramente foram vistos de forma isolada e, frequentemente, estavam associados a uma outra condição. No ambulatório de GM, houve discreta prevalência de Atraso do Desenvolvimento Neuropsicomotor (ADNPM), com 8 registros e, em apenas 2 casos, o ADNPM figurava como única doença diagnosticada no paciente. Nos outros 6 , estava

RC: 79751

Disponível em: https://www.nucleodoconhecimento.com.br/saude/ambulatorio-degenetica 
associado a baixa estatura e dismorfia (3), hipotiroidismo congênito (1) e puberdade precoce (2). Algumas síndromes foram encontradas, como síndrome Dismórfica (3), síndrome de Noonan (3), síndrome de Cornelia Lange (2), síndrome de Sotos (2), síndrome de Charge (1), síndrome de Marfan (1), síndrome de Aarskog (1), síndrome de Down (1), síndrome de Beckwith-Wiedermann (1), síndrome de Turner (1), síndrome de Prader-Willi (1), síndrome de Williams (1) e síndrome hipercinética associada ao transtorno do déficit de atenção e hiperatividade (1). Foram encontrados 5 casos de cromossomopatias 46, XY e outros 5 de deficiência intelectual sindrômica. Além de 4 registros de investigação de embriopatia por Zyka vírus, 3 investigações de doença familiar, sendo 2 cânceres de mama em irmãs. Erros inatos do metabolismo representaram 4 casos, assim como baixa estatura de herança autossômica dominante. Acondroplasia, X-frágil e epilepsia associada a déficit cognitivo totalizaram 3 pacientes cada. Também, neoplasia endócrina múltipla tipo 1 e neoplasia endócrina múltipla tipo 2A, microtia unilateral direita, megacólon congênito com alterações esqueléticas, lipodistrodia parcial tipo Dunning com oligomenorreia, neuropatia hereditária distal e neurofibromatose apresentaram 1 caso cada (Figura 5).

Outras condições encontradas foram: exostose múltipla (2), hiperplasia adrenal congênita (2), acidemia metilmalônica (1), adrenoleucodistrofia ligado ao $X(1)$, alteração de comportamento multifatorial (1), artrogripose de predomínio distal associado a sinais de brida (1), atraso no desenvolvimento sexual por hipogonadismo (1), bronquectasia não-fibrótica (1), doença de Dohi (1), deficiência de hormônio do crescimento com baixa densidade mineral óssea com síndrome miastênica associada a síndrome de Kearnes-Sayre (1), hipotireoidismo central com mielose funicular e microadenoma hipofisário (1), carcinoma medular de tireoide (1), encefalopatia crônica não progressiva (1), fibrose cística (1), genodermatose associada a linfedema (1) e hipodistrofia (1) (Figura 5). Dentro do período de coleta de dados, 10 pacientes seguiam em investigação ou sem diagnóstico concluído.

RC: 79751

Disponível em: https://www.nucleodoconhecimento.com.br/saude/ambulatorio-de- 
Figura 5: Distribuição dos pacientes atendidos no ambulatório de Genética Médica, por diagnóstico.

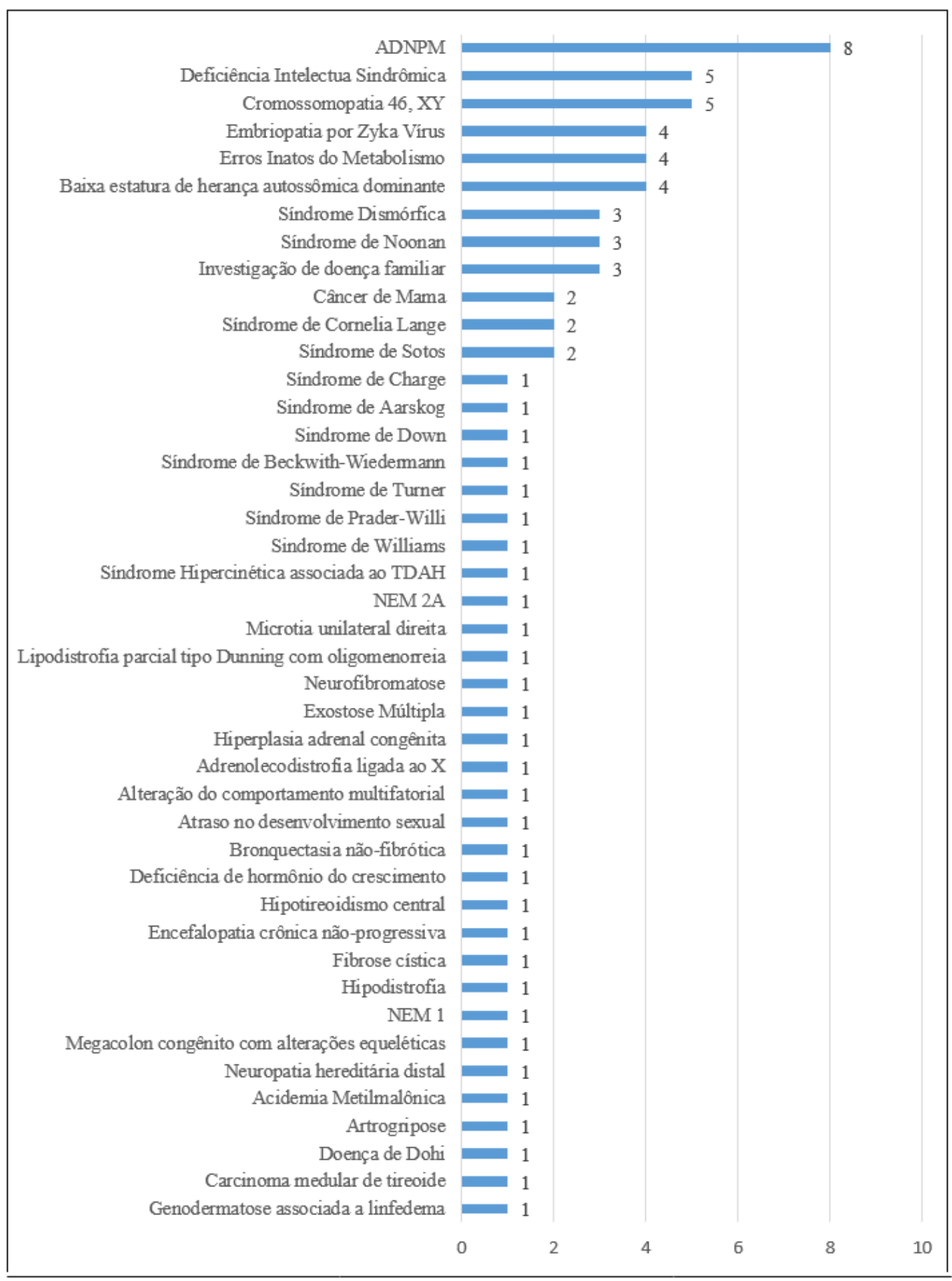

Fonte: Dados da pesquisa.

RC: 79751

Disponível em: https://www.nucleodoconhecimento.com.br/saude/ambulatorio-de- 
Em 42 prontuários a idade ao diagnóstico não estava presente, 2 pacientes receberam o diagnóstico ainda intra-útero e outros 4, ao nascimento. Outros 11 pacientes foram diagnosticados com idade inferior aos 2 anos; 13 pacientes, entre 2 e 9 anos; 18 durante a adolescência, com maior número aos 14 anos, com 6 diagnósticos. Na faixa etária adulta foram 11 diagnósticos e apenas 1 em paciente idoso, aos 63 anos (Figura 6).

Figura 6: Distribuição dos pacientes atendidos no ambulatório de Genética Médica, por idade ao diagnóstico.

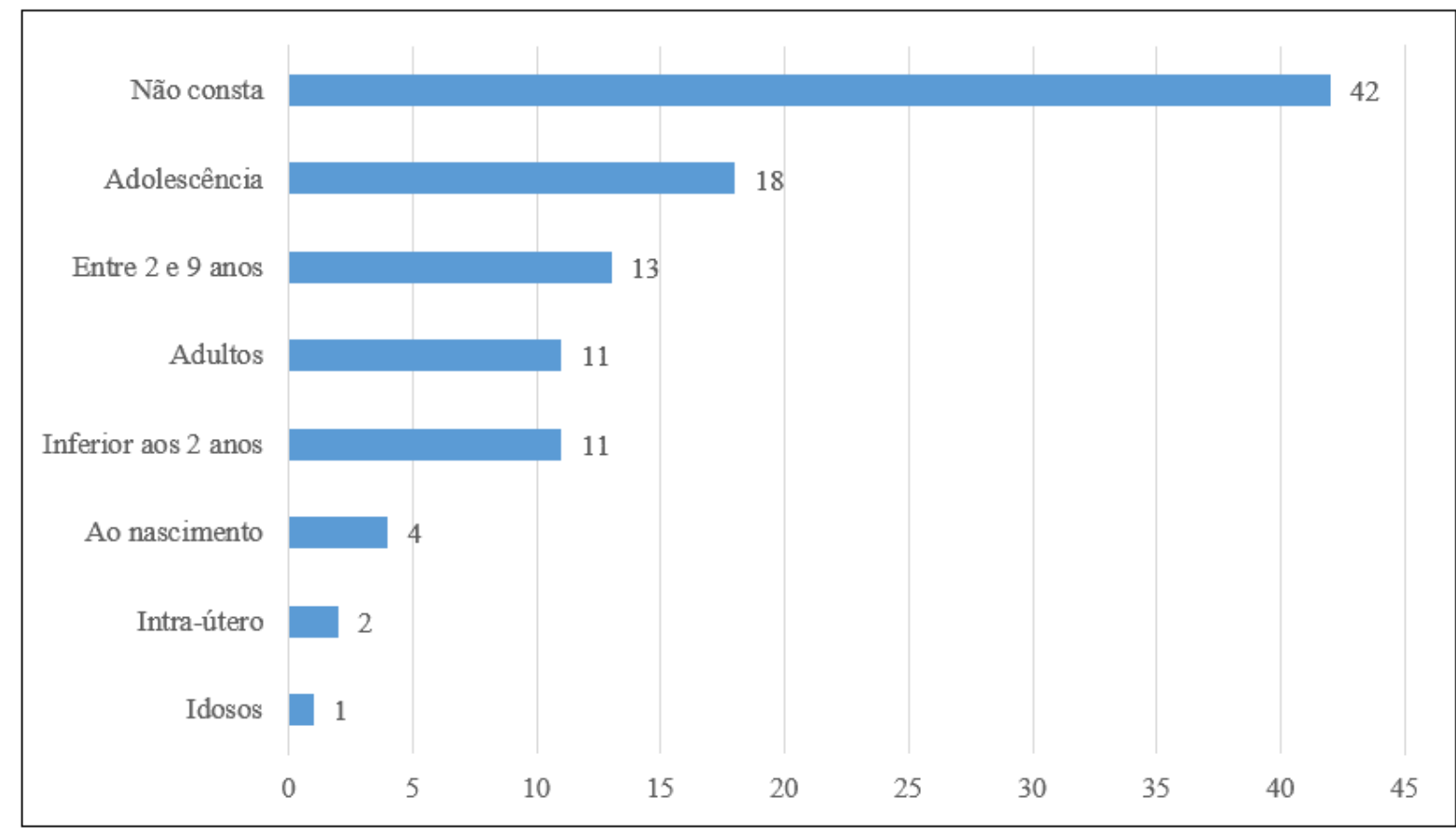

Fonte: Dados da pesquisa.

Dos 101 pacientes, somente 16 tiveram aconselhamento genético e nos 85 restantes não havia registro sobre esta informação.

Os pacientes foram mais frequentemente acompanhados pela Endocrinologia, sendo 21 registros, seguidos da Neurologia com 20 pacientes e a Psicologia acompanhou 7 pacientes. Além disso, 5 pacientes faziam acompanhamento com a

RC: 79751

Disponível em: https://www.nucleodoconhecimento.com.br/saude/ambulatorio-de- 
Gastrologia, 4 com a Genética, Otorrino e Ortopedia, outros 3 com a Pediatria, 2 com Terapia Ocupacional, 2 pela Fisioterapia e Terapia Ocupacional simultaneamente, $2 \mathrm{com}$ a Clínica Médica, $2 \mathrm{com}$ a Mastologia, $1 \mathrm{com}$ a Fonoaudiologia, $1 \mathrm{com}$ a Nutrição, $1 \mathrm{com}$ a Dermatologia, $1 \mathrm{com}$ a Pneumologia e 1 com a Saúde do Idoso. Além disso, 18 prontuários não tinham a variável preenchida e 2 não faziam acompanhamento (Figura 7).

Gráfico 7: Distribuição dos pacientes atendidos no ambulatório de Genética Médica, por acompanhamento.

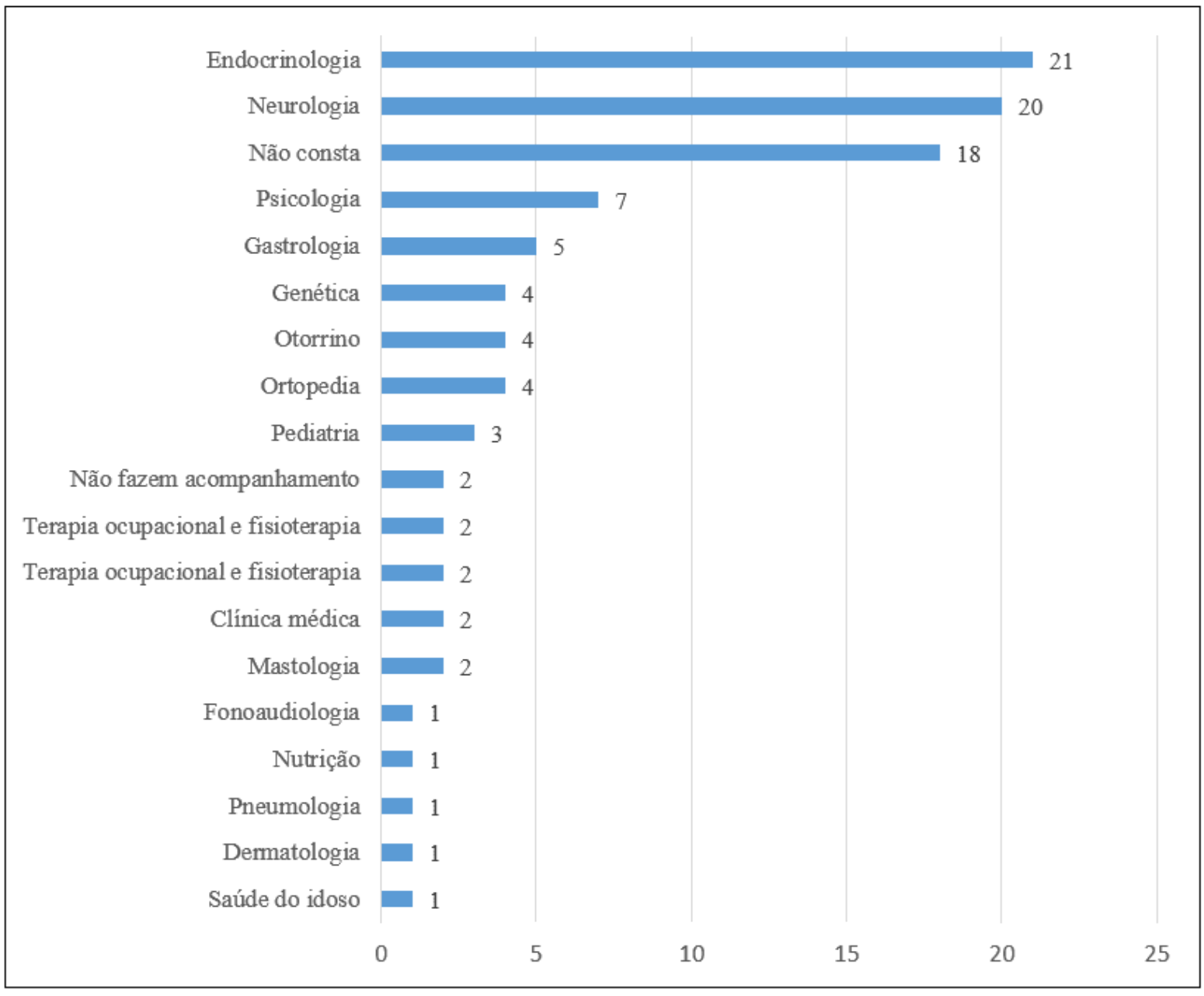

Fonte: Dados da pesquisa.

RC: 79751

Disponível em: https://www.nucleodoconhecimento.com.br/saude/ambulatorio-degenetica 
A informação sobre a idade da mãe estava ausente na maioria dos prontuários, não constando em $61,38 \%$ do total. Nos prontuários em que a informação estava presente $(38,62 \%)$, idades maternas entre 16 e 19 anos totalizaram 7,92\%, enquanto que idades entre 20 e 59 anos estavam em $30,7 \%$ dos registros.

Em 36 prontuários não havia informações sobre intercorrências durante a gestação e em 25 casos não houveram intercorrências. Os que tiveram (40) foram variadas: infecção do trato urinário (8), sangramento uterino (6), nascimento pré-termo (5), pré-eclâmpsia (4), demora nas contrações de expulsão do feto (2), oligodrâmnio (2), anóxia perinatal (1), cianose central (1),cólica nefrética (1), criança presa no canal de parto (1), descolamento de placenta (1), dores durante a gestação (1), etilismo e tabagismo (1), internação por crise asmática materna (1), mordedura canina (1), tabagismo, metrorragia e criança com onfocele na USG - na mesma paciente - (1), uso de tintura capilar e descoloração dos pelos corporais (1), varicela (1), e Zyka vírus materno (1).

\section{DISCUSSÃO}

Belém é um município brasileiro, capital do Estado do Pará, situado na região Norte do país, mais especificamente na região da Amazônia brasileira. É o município mais populoso do Pará e o segundo da região Norte, com uma população de 1. 492.745 habitantes (INSTITUTO BRASILEIRO DE GEOGRAFIA E ESTATÍSTICA, 2020). A cidade possui uma rede econômica e de serviços - inclusive de saúde - que atende às cidades da sua região metropolitana.

Considera-se que seja necessário um médico Geneticista para cada 100.000 habitantes, contemplando $o$ atendimento ambulatorial, hospitalar e aconselhamento genético (CARVALHO et al., 2016; CONSELHO FEDERAL DE MEDICINA, 2020). No Estado do Pará, atualmente, apenas 3 médicos estão exercendo a especialidade de GM, de acordo com os dados do Conselho Federal de Medicina (CONSELHO FEDERAL DE MEDICINA, 2020). Além disso, todos atuam na capital paraense.

RC: 79751

Disponível em: https://www.nucleodoconhecimento.com.br/saude/ambulatorio-de- 
Dessa forma, nota-se a escassez do serviço, uma vez que a especialidade beneficia toda a coletividade e agiliza o sistema de saúde. Isso porque o diagnóstico precoce das doenças de origem genética permite um melhor manejo dos pacientes e impede ou minimiza eventuais sequelas e também reduz custos com possíveis tratamentos mais complexos.

Outro dado relevante apontado pelo estudo é a carência da realização do aconselhamento genético pela equipe multiprofissional que assiste o paciente, uma vez que apenas cerca de $16 \%$ dos pacientes tiveram acesso a esse serviço, para os demais, a informação estava ausente. Tal fato pode estar relacionado a escassez do serviço, uma vez que nem todos os pacientes com doença genética tem o serviço à sua disposição, sendo necessário ampliar a rede de atendimentos a esse público, dada a importância do aconselhamento multiprofissional, especialmente no que diz respeito à prevenção de genótipos responsáveis por enfermidades ou defeitos congênitos (JORDE; CAREY; BAMSHAD, 2016).

O estudo também revelou a alta taxa de encaminhamentos entre a GM e outras especialidades do Centro Médico em que a pesquisa foi realizada. As especialidades com maior número de encaminhamentos foram a Endocrinologia e a Neurologia, além de serem observados o encaminhamento da GM para outros profissionais, como psicólogos e terapeutas ocupacionais. Sendo, portando, notória a importância de abordagem multiprofissional dos pacientes, uma vez que algumas doenças genéticas cursam com acometimentos de um ou mais sistemas do organismo (BERTOLLO et al., 2013).

No tocante a idade materna ao nascimento do paciente, mais da metade dos prontuários não continham a informação (62 prontuários), porém, os prontuários que apresentavam esse dado, revelaram que a idade da mãe era maior que 35 anos em 6 prontuários. Esse dado se torna relevante, uma vez que estudos indicam uma associação entre a idade materna avançada e o desenvolvimento de desordens genéticas. Estudos revelam que a prevalência de complicação genética em fetos de

RC: 79751

Disponível em: https://www.nucleodoconhecimento.com.br/saude/ambulatorio-de- 
mães com 20 anos é de 1 a cada mil, ao passo que, aos 35 anos, essa proporção chega a 1 a cada 350 gestantes. Mais uma vez corroborando a importância do aconselhamento genético (MENDES, 2017; BARBOZA et al., 2020).

\section{CONCLUSÃO}

A elaboração de um perfil para o paciente atendido em um ambulatório de Genética Médica é de extrema importância, uma vez que, a partir desse conhecimento, tornase possível identificar eventuais falhas no serviço prestado, além de adequar a relação médico-paciente. Ressalta-se também que a aceitação e execução correta do tratamento e acompanhamento de uma doença genética dependem de fatores pessoais e sociais, assim como da fase em que a doença está contemplando a continuidade do tratamento. Dessa forma, corrobora-se a necessidade de determinar o perfil do paciente que está sendo tratado.

Assim, os resultados do presente estudo demonstraram a importância do preenchimento adequado do prontuário do paciente atendido no ambulatório de Genética Médica, com o intuito de evitar a perda de informações cruciais, que podem ajudar a determinar o diagnóstico ou auxiliar na condução do caso no seguimento do paciente.

Outro fator importante ressaltado durante o estudo é a frequente sobreposição de diagnósticos, uma vez que os pacientes costumam cursar com mais de uma patologia, é importante particularizar o atendimento, atentando-se a esse fato, a fim de evitar possíveis iatrogenias e intercorrências, com interações medicamentosas durante o tratamento.

RC: 79751

Disponível em: https://www.nucleodoconhecimento.com.br/saude/ambulatorio-de- 


\section{REFERÊNCIAS}

BARBOZA, B. P.; CALIL, C.; TRIGO, I. G. P. F.; ELLER, J. X.; SILVA, L. R.; VAZ, M. R.; ESTEVES, A. P. V. S. Idade materna avançada e seus desfechos. Cadernos da Medicina-UNIFESO, v. 2, n. 3, 2020.

Bertollo, E. M. G.; CAStRo, R; CINTRA, M. T. R.; PAVARINo, É. C. O processo de aconselhamento genético. Arq. Cienc. Saúde, v. 20, n. 1, p. 30-6, 2013.

BORGES-OSÓRIO, M. R; ROBINSON, W. M. Genética Humana. 3ª edição, Porto. Alegre, Editora Artmed, 2013.

CARVAlHo, A. C.; VIEIRA, E.; ALTENHOFEN, T. M. G.; JUNG, M. S. Perfil clínicoepidemiológico dos pacientes atendidos pelo Serviço de Genética Médica do Ambulatório Materno Infantil da Universidade do Sul de Santa Catarina. Arquivos Catarinenses de Medicina, v. 45, n. 2, p. 11-24, 2016.

CONSELHO FEDERAL DE MEDICINA. Disponível em: < https://sistemas.cfm.org.br/normas/arquivos/pareceres/BR/2018/17_2018.pdf > Acesso em 20 de março de 2020.

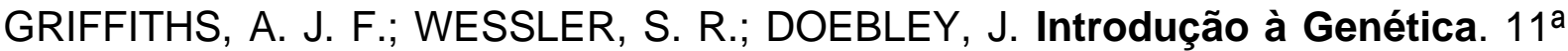
edição. Guanabara Saúde Didático, 2016.

INSTITUTO BRASILEIRO DE GEOGRAFIA E ESTATÍSTICA. Disponível em: $<$ https://www.ibge.gov.br/cidades-e-estados/pa/belem.html> Acesso em: 20 de março de 2020.

JORDE, L. B.; CAREY, J. C.; BAMSHAD, M. J.; Genética Médica. 5ª edição, Rio de Janeiro, Editora Elsevier. 2016.

RC: 79751

Disponível em: https://www.nucleodoconhecimento.com.br/saude/ambulatorio-degenetica 
LOBO, I. Environmental influencies on gene expression. Nature Education 1(1):39, 2008.

MENDES, C. C. Estudo genético e epigenético de fatores de risco materno para a síndrome de Down. 2017. 32 f. Tese (Programa de Pós-Graduação em Ciências da Saúde) - Faculdade de Medicina de São José do Rio Preto, São José do Rio Preto.

NUSSBAUM, R. L.; MCINNES, R. R.; HUNTINGTON, F. W.; THOMPSON, M. W. Thompson \& Thompson. Genetics in Medicine. Philadelphia: Elsevier. 2016.

SOCIEDADE BRASILEIRA DE GENÉTICA MÉDICA. Disponível em: <http://www.sbgm.org.br>. Acesso em: 20 março, 2020.

ZANELLA, J.; TERENCIO, M. L. Genética clínica: investigação dos padrões de herdabilidade de doenças humanas-mutações genéticas e cromossômicas. Artigo completo publicado em: Anais do V Encontro de Iniciação Científica e I Encontro Anual de Iniciação ao Desenvolvimento Tecnológico e Inovação - EICTI. 2016.

Enviado: Março, 2021.

Aprovado: Março, 2021.

RC: 79751

Disponível em: https://www.nucleodoconhecimento.com.br/saude/ambulatorio-de- 